\title{
The Research of Kang Gully Mudflow's Formation Mechanism in Weinan
}

\author{
Weilong GUO \\ School of Geological engineering and Geomatics \\ Chang'an University \\ Key laboratory of Geological Resources and Geological \\ Engineering Ministry of Education \\ Xi'an, China \\ e-mail: guoweilong0426@163.com \\ Dawei ZHANG \\ School of Geological engineering and Geomatics \\ Chang'an University \\ Key laboratory of Geological Resources and Geological \\ Engineering Ministry of Education \\ Xi'an, China \\ e-mail: 275996659@qq.com
}

\begin{abstract}
There are many gullies in loess area, if enough incompact soil accumulates in gully, it will cause mudflow when encountering heavy rains. Kang gully located in transition of loess tableland and terrace of Weihe River in Weinan, has a larger longitudinal grade, intense erosion of ground water, and abundant source in gully, many mudflows have occurred. Through field investigation and analysis we think: The landform of Kang gully provides spatial condition to formation of mudflow; Planar erosion and gravity erosion for the slope on either side of gully have accumulation effect for material source of mudflow, blocking and burst phenomenon amplify the scale of mudflow, nevertheless, larger mudflow erodes to the slope toe; landslides on either side of gully and mudflow in Kang gully successively occurred under the influence of rainstorm excitation, and they promote each other, thereby forming more destructive landslidemudflow-barrier lake-landslide, which is primarily a mudflow geohazard chain.
\end{abstract}

Keywords-loess mudflow; planar erosion; gravity erosion; blocking and burst effect; formation mechanism; geohazard chain

\section{INTRODUCTION}

Loess area is one of the regions with the most serious soil erosion and the most fragile ecological environment. Surface loess has the features of loose structure and inferior ability to resist erosion, therefore, through long-term water erosion there are thousands of gullies and fragmented landforms and physiognomy in loess area [1-2]. Associated with this phenomenon the corresponding geological hazards have occurred: landslides and mudflows are the two most frequent and widespread serious geohazards. In recent years, with indepth research, many scholars have found that there are close connections between landslides and mudflows, as landslides translate to debris flow. This problem includes two parts: (1)

\author{
Yuxiang CHENG \\ School of Geological engineering and Geomatics \\ Chang'an University \\ Key laboratory of Geological Resources and Geological \\ Engineering Ministry of Education \\ Xi'an, China \\ e-mail: 853660428@qq.com
}

\section{Lan LI}

School of Geological engineering and Geomatics Chang'an University

Key laboratory of Geological Resources and Geological Engineering Ministry of Education Xi'an, China

e-mail: 1505302091@qq.com

the problem of landslides translating to slope debris flow. (2) the problem of landslides translating to debris flow in ravines. The former is the theory that landslides translating to debris straightly in motor process, much of the research about this has been done by experts both at China and abroad, and established a relatively complete theoretical system, represented by Cui Peng, Dai Fuchu, ect, at China, and represented by Sassa, Hungr, Iverson, Okura, Fleming, ect, at abroad [3-4]. However, comparing with the form, the problem that landslides translating to debris flow in ravines have more complex processes, that is: slope failurelandslide move-accumulation stack in gully-forming debris flow in ravines. In some sense, this is the problem of restart the accumulation, Takahashi [5-6] studied hydrodynamic start but ignored the influence of pore water pressure and seepage pressure to debris flow's startup; and Iverson's [7-9] study emphasized pore water pressure but ignores the effect of seepage pressure on debris flow's startup. So our study is not perfect for landslide translating to debris flow in ravines. Our study of this issue has very important significance to the cognition of regional debris flow and the forecast of scale. There are 21 old-landslide in Kang gully catchment, this paper takes Kang gully catchment as a research area, study and analysis of the formation mechanism of Kang gully mudflow, and discusses the transforming mechanism of loess landslide translating to mudflow in ravines.

\section{FORMING CONDITION OF KANG GULLY MUdFLOW}

\section{A. Geomorphologic Conditions}

Kang gully located in transition of loess tableland and terrace of Weihe River in weinan, the landform from the boundary of catchment to channel is a concave terrain. The area of catchment is $3.5 \mathrm{~km}^{2}$, valley's length is $3.2 \mathrm{~km}$, 
relative elevation is $292 \mathrm{~m}$, longitudinal slope is $40 \%$, and the shape of the gully's cross-section is "V".

\section{B. Hydrological Conditions}

There is relatively concentrated rainfall in the study area, mainly concentrated in 6 9 month, attainable annual average precipitation is $962.2 \mathrm{~mm}$. On average there may be 0.6 heavy rain, mainly concentrated in 7,8 month. According to the statistics from 1980 to 2014 , on average there are 3.1 continuous rain every year, the longest sustain 18 days, mainly concentrated in 7,9 month.

\section{Condition of Material Source}

There distribute 21 old-landslide along the both sides of the gully, a mass of Quaternary Holocene saprolite and slope wash $\left(\mathrm{Q}_{4}{ }^{\mathrm{el}+\mathrm{dl}}\right)$ are dispersed over the middle and lower area of the slope from both sides of the gully, thickness is $3 \sim 7 \mathrm{~m}$. Quaternary Holocene alluvium and diluvium $\left(\mathrm{Q}_{4}{ }^{\mathrm{al}+\mathrm{pl}}\right)$ mainly are dispersed over the bottom of the gully, thickness is 1.5 2m. And 10 15m thick Quaternary upper Pleistocene eolian deposit $\left(\mathrm{Q}_{3}{ }^{\mathrm{eol}}\right)$ are dispersed over plateau of both sides of the gully, there are many fissures dispersed over the edge of the plateau, under the effect of water erosion, some fissures become wider and bigger and can even evolve into ponor. There is outcrop of sandy mudstone in the lower gully, sandy mudstone is a relative confining bed, its appearance underwent strong weathering, so its structure is very loose and its strength is very low (Figure1).
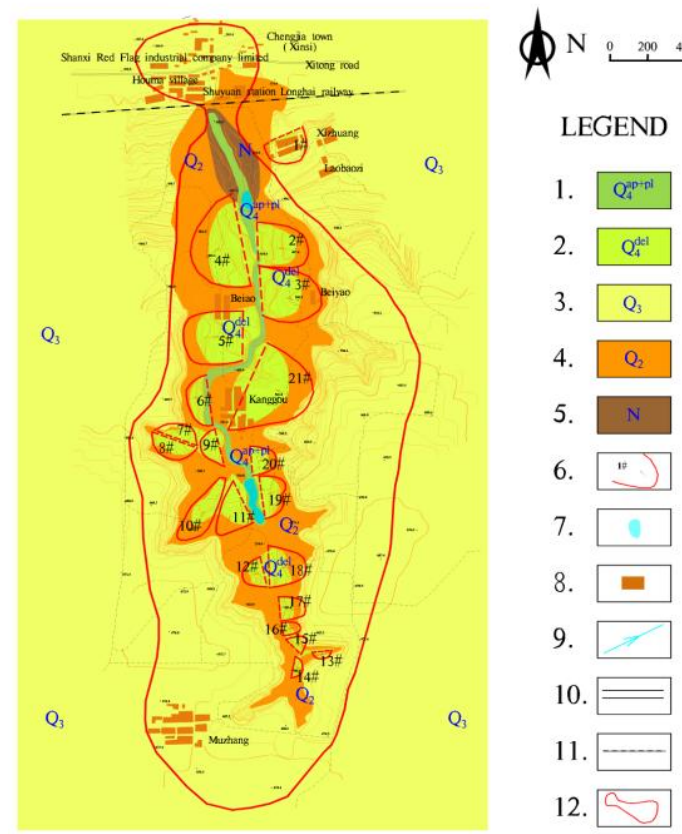

Figure 1. Geological map of Kang gully catchment (1.quaternary holocene alluvium and diluvium 2.quaternary holocene saprolite and slope wash 3.quaternary upper pleistocene eolian deposit 4.quaternary middle pleistocene eolian deposit 5.neogene sandy mudstone 6.old-landslide 7.reservoir 8.village 9.river 10. road 11.railway 12.the range of catchment)

\section{SUPPLIES OF MATERIAL SOURCE}

Due to its dispersed abundant loose soil mass and steep slope in Kang gully catchment, and concave landform, rainwater can be quickly collected in the gully, under the effect of water erosion, the phenomenon of planar erosion and gravity erosion [10-12], appears so mass soil is carried into the gully and stacked up over there, the sliding mass block up channel forming a barrier lake.

\section{A. Accumulative Effect of Planar Erosion on Material Source of Mudflow}

In Kang catchment, the movement of old-landslides left staggered step on back wall and side wall of landslide, this step form negative relief on slope, rainwater be collected in this negative relief during rain, and forms a channel on the slope. Movement of landslides leads to staggered soil, the boundary between eolian deposit and slop wash exposed in channel; however this part's ability to resist erosion is the most inferior [10].

At present, many scholars believe that the separating capacity of runoff is in direct proportion to effective shear force [13]. Under the condition of continuous rain, the loose soil mass can be saturated by rainwater. Water weakens the connecting force between each grain of soil mass, soil in suspending - semi-suspending state, ability to resist erosion of soil mass become weak and even disappeared. After runoff on the slope is formed, a shear force of runoff along gradient direction of slope generates [14], the structure of the soil mass is destroyed, and soil grain is dispersed, the dispersed soil grain or soil mass is then carried in runoff and rushed off of the slope. The formula of runoff shear force is:

$$
\tau=\gamma \mathrm{R} \mathrm{J}
$$

where $\tau$ is the runoff shear force $(\mathrm{kPa}) ; \gamma$ is the unit weight of fluid $\left(\mathrm{kN} / \mathrm{m}^{3}\right) ; \mathrm{R}$ is hydraulic radius $(\mathrm{m}) ; \mathrm{J}$ is hydraulic gradient(dimensionless). With the slope gradually eroding, solid material is continually put into runoff, the shear force is increased with the increasing of weight of runoff, the erodent capacity is increased as well [13, 15-16]. Solid material cascades into the gully along steep slopes and stacks up at there.

\section{B. Accumulative Effect of Gravity Erosion on Material Source of Mudflow}

There are large thick and poorly consolidated loess in Kang gully catchment, owing to gravity erosion being very active, a mass of loose soil mass can be stacked in the middle and lower parts of the slope from both sides of gully. Because both sides of the slope are eroded seriously by water, the slope is cut into broken pieces. Due to the combined effects of gravity erosion and water erosion, collapse and landslide occur at the side of the slope that faces the gully during rain. The relationship between the shear force of the slope subjected and the shear resistance of slope determines the stability of soil mass. There are known old-landslide on slope, we simplify this problem under the condition of established sliding surface, so the stability of soil mass could be expressed as: 


$$
f=\frac{\tau}{\tau_{f}}=\frac{\gamma h \sin a}{\gamma h \cos a \tan \varphi+c}
$$

where $\mathrm{f}$ is the coefficient of stability; $\tau$ is the shear force $(\mathrm{kPa}) ; \tau_{\mathrm{f}}$ is shear resistance $(\mathrm{kPa}) ; \gamma$ is the unit weight of soil mass $\left(\mathrm{kN} / \mathrm{m}^{3}\right) ; \mathrm{h}$ is the average thickness of soil above sliding surface $(\mathrm{m}) ; \alpha$ is the angle of sliding surface $\left({ }^{\circ}\right) ; \varphi$ is the internal friction angle of soil mass $\left({ }^{\circ}\right)$; $\mathrm{c}$ is cohesion of soil mass $(\mathrm{kPa})$ [17]; when $\mathrm{f}$ less-than 1 , gravity erosion would happen.

In rainstorms, lots of rain infiltrates loose soil mass on the surface of the slope, due to the porosity of undisturbed loess compared with the saprolite and slope wash is much smaller, rainwater can't discharge in time, and the positive pore pressure would appear in soil mass, and disturbing hydraulic pressure loads caused by the high intensity rainfall destroys the soil mass structure [18], the stability of soil mass would be inferior, lots of saprolite and slope wash would slide into the gully because of gravity; on the other hand, malan loess where dispersed over the back wall of the landslide has many fissures, eroding both sides of the fissure by water which continuously permeates through soil mass, some fissures cut through the sliding-zone, surface water permeates into phreatic water, eventually forming hydraulic linking even ponor, decreasing the stability of the slope, lots of soil mass becomes potential material source of mudflow. When mudflow starts in the gully, this solid material joins into mudflow, and then enhances the eroding capacity of runoff, afterwards eroding the slope toe, owing to this landslide would restart easier [19], soil mass would slide into the gully and then forge new material source(Figure 2).

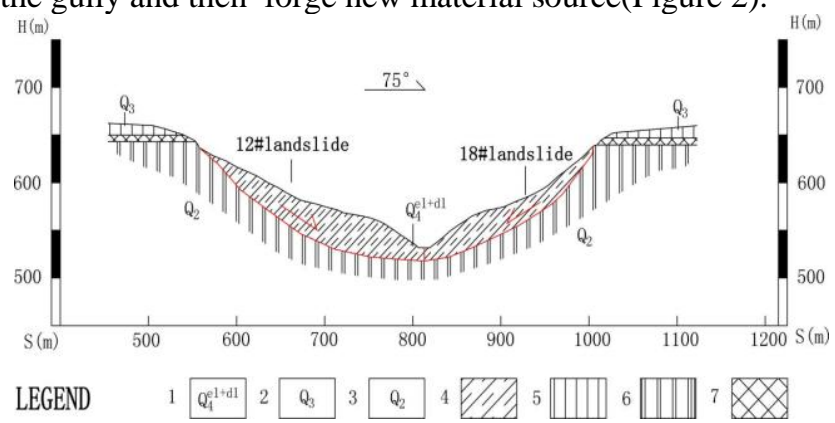

Figure 2. Slope wash stack into gully under the effect of gravity erosion (1.quaternary holocene saprolite and slope wash 2.quaternary upper pleistocene eolian deposit 3.quaternary middle pleistocene eolian deposit 4.silty clay 5.loess of malan 6.paleosoil)

\section{Amplification of Blocking and Burst Effect on Material Source of Mudflow}

There are larger old-landslides in Kang catchment, especially the landslides which are face-to-face across the gully slides into gully, lots of slope wash occupies the channel, and then forms a blocking; on the other hand, because of the movement of the landslide, slope wash occupies channel, and then forms some narrow "U", "V"curves, abundant solid material accumulates by planar erosion and gravity erosion stacked into a narrow channel, the speed of the mudflow is slower when the mudflow flows to these curves, runoff energy is then consumed more, if the capacity of transportation lessens than the capacity to carry sediment, lots of solid material would stagnate and deposit up to silt the channel.

Kang gully has a larger longitudinal slope by about $40 \%$, it provides higher potential energy for blocked material, and the more material, the higher potential energy, and then the block more easily bursts; most of the blocked material is loose saprolite and slope wash, and the intense permeation and runoff of surface water provides buoyancy force loads and seepage pressure loads to block, it is easy causes that block loses its structure and burst; with more and more material from upstream being blocked until overflowing the clog, hydrodynamic pressure, water pressure and shock pressure are added to the block so that the structure of the block is destroyed and bursts [10].

During the process of blocking - burst, the energy carried by runoff from upstream is accumulated into this small zone. When the accumulative energy reaches the critical point, this energy bursts and sequentially causes larger mudflow than before, therefore muldflow obtain more intense erosion capacity to erode slope toe and cause old-landslide reactivation, and enhanced mudflow would has the deeper and more intense erosion to the bottom of channel (Figure 3).

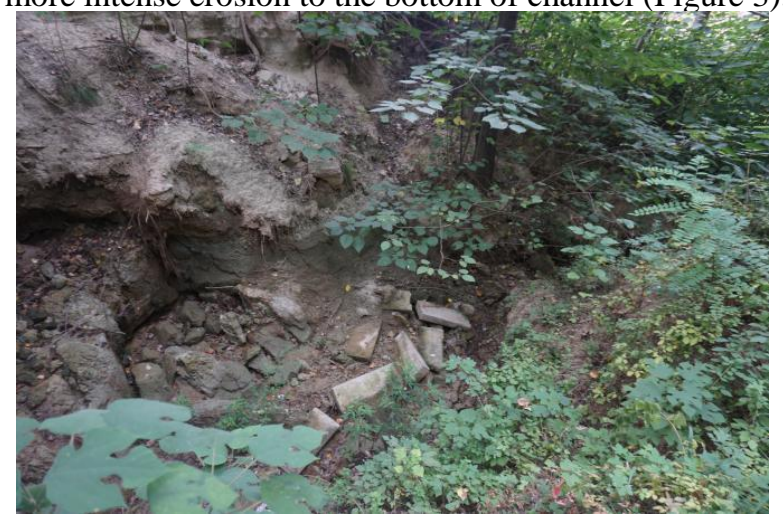

Figure 3. Mudflow deeply erodes the bottom of channel after the burst

\section{FORMATION MECHANISM OF KANG GULLY MUDFLOW}

Coupled effect of planar erosion and gravity erosion made the soil mass above the slope on both sides of the gully eroded and fragmented, under the effect of runoff and gravity, this loose soil mass of slope wash and seriously efflorescent malan loess on surface slope and gully would be carried into the channel, lots of solid material accumulates in channel and forming block at some locality. In rainstorms and continuous rain, abundant rainwater is quickly collected into gully, loose sediment on the bottom of the channel first starts and forms mudflow under the bigger hydrodynamic condition, when the mudflow flows to block along the channel, the mudflow stagnates there and continuously accumulates energy until reaching the critical point of burst, the mudflow then obtains greater flow, velocity and collapsing force, meanwhile the mudflow's erosion capacity is continuously enhanced, and the mudflow deeply erodes the bottom of the channel, carries deeper material into runoff, and erodes slope toe causing new free face, the slope on both sides of the gully becomes 
unstable, old-landslides may reactivate with planar erosion and gravity erosion during rain, thus lots of soil mass slides into the channel to form a new block which has a larger capacity and greater destructive after burst, further enhancing the scale and collapsing force. Eventually forming an integrated geohazard chain: landslide-mudflow-barrier lake-landslide [19-22].

\section{CONCLUSION}

(1) There are landform, geomorphy and material source condition could meet the requirement of mudflow in Kang gully catchment, it is easily to trigger mudflow once encounter heavy rain.

(2) Most of material source derived from concentrated supply of the planar erosion on the ground and gravity erosion on the slope wash.

(3) The blocking and burst effect of slip mass has amplification for scale of mudflow.

(4) Mudflow and landslide promote each other, forming geohazard chain.

\section{ACKNOWLEDGMENT}

This work was supported by the Project of the National Natural Science Foundation of China (Grant No: 41672255), the National Natural Science Youth Fund Project (Grant No: 41302250), the Fundamental Research Funds for the Central Universities Project (Natural Science) (No: 310826161002$).$

\section{REFERENCES}

[1] Junan Chen, "The study of loess erosion's forecast from the condition of geomorphy", Yellow River, No. 03, pp. 59-61, 1988. (in Chinese)

[2] Weinan Chen, "The analyses of loess erosion influenced by Geomorphologic conditions in loess ridge region", Scientia Geographica Sinica, Vol.8, No.4, pp. 323-329+395, nov. 1988. (in Chinese)

[3] Zili Feng, Peng Cui, Siming He, "Mechanism of conversion of lanfslides to debris flows", Journal of Natural Disasters, Vol. 14, No. 3, pp. 8-14, Jun. 2005. (in Chinese)

[4] Xiaoqing Chen, Yong Li, Peng Cui, "An overview of transformation of lanfslide into debris flow", Journal of Mountain Science, Vol. 22, No. 5, pp. 562-567, Sep. 2004. (in Chinese)

[5] Takahashi T, "Mechanical characteristics of debris flow", Journal of the Hydraulics Division, HY8, pp. 1153-1169, 1978.

[6] Takahashi T, "Debris flow" Annual Review of Fluid Mechanics, vol. 13, pp. 13:57-77, 1981.
[7] Iverson R M, "New views of granular mass flows", Geology, vol. 29, No. 2, pp. 115-118, 2001.

[8] Iverson R M, "landslide triggering by rain infiltration", Water Resources Research, Vol. 36, pp. 1897-1910, 2000.

[9] Iverson R M, "Flow of variably fluidized granular masses across three-dimensional terrain 1. Coulamb Mixture theory", Journal of Geophysical Research, Vol. 106, No. B1, pp. 537-53, 2001.

[10] Hongbing Hao, Songjiang Zhao, Shengwei Li, Dehua Li, Nan Cao, "The star-up mode on large debris flow material source in Wenchan earthquake region", Hydrogeology and Engineering Geology, Vol. 42, No. 6, pp. 159-165+170, Nov. 2015. (in Chinese)

[11] Wenjin Xie, "The analyses of rock-soil erosion and category in middle reaches of the yellow river", Huabei land and resources, pp. 56-57, Jan. 2015. (in Chinese)

[12] Yingsheng Dai, "Basic laws of soil erosion in the middle reaches of the Yellow River", Yellow River, pp.47-54, Jan. 1985. (in Chinese)

[13] Wen Li, "Experimental study on the runoff erosion process on slope", Xi'an University of Science and Technology, 2006. (in Chinese)

[14] Ting Luo, Wenlong Wang, Zhen Wang, Jian Jin and Hao Wang, "Analysis on rate of soil denudation and parameters of hydrodynamics of non-hardened dirt roads", Yellow River, Vol. 33, No. 4, pp. 96-98+101+151, Apr. 2011. (in Chinese)

[15] Weiqun $\mathrm{Xu}$, Jinren $\mathrm{Ni}$, Haipeng Xu, Desheng Jin, "Experimental study on erosion process over loess slopes I. Surface flow and sediment transport", Journal of soil and water conservation, Vol. 9 , No. 3, pp. 9-18+77, Sep. 1995. (in Chinese)

[16] Weiqun $\mathrm{Xu}$, Jinren Ni, Haipeng Xu, Desheng Jin, "Experimental study on erosion process over loess slopes II. Slope form transport", Journal of soil and water conservation, Vol. 9, No.3, pp. 19-28, Sep. 1995. (in Chinese)

[17] Jishan Yang, Wenyi Yao, Lingling Wang, "Study on the regularity and mechanism of gravity erosion in the loess gully", Yellow River, Vol. 36, No. 6, pp. 93-96, Jun 2014. (in Chinese)

[18] Anderson. S. A., Sitar. N, "Analysis of rain-induced debris flows", Journal of Geotechnical Engineering ASCE, vol. 121, no. 7, pp. 544553,1995

[19] Mingxu AN, Tingfang Chen, Huiqiang Yang, Youyong Peng, "research on relations among landslide, collapse and debris flow", Technology of Highway and Transport, No. 02, pp. 13-15+19, April 2014. (in Chinese)

[20] Ming Li, Hongmei Tang, Siqiao Ye, "Research on chain rule of typical geological disaster", Journal of Catastrophology, Vol. 23, No. 1, Mar. 2008. (in Chinese)

[21] Jinliang Han, Shuren Wu, Huabin Wang, "Preliminary study on geological hazard chain", Earth Science Frontiers, Vol. 14, No. 6, pp. 11-23, Nov. 2007. (in Chinese)

[22] Yutao Feng, Shengxie Xiao, "Chain mechanism and optimized control of collapses, landslides and debris flows", Journal of Catastrophology, Vol. 24, No. 3, Sep. 2009. (in Chinese) 